\title{
ESTUDO DA INFLUENCIA DA TEMPERATURA NA RESISTÊNCIA AO ETANOL DA LEVEDURA Saccharomyces cerevisae $\mathrm{Y} 904$
}

\author{
M. L. CRUZ ${ }^{1}$; M. L. F. RAMINHO ${ }^{1}$; A. L. M. CASTRO ${ }^{1}$; C. Z. GUIDINI ${ }^{1}$; \\ M. M. de RESENDE ${ }^{1}$; E. J. RIBEIRO ${ }^{1}$; \\ ${ }^{1}$ Universidade Federal de Uberlândia, Faculdade de Engenharia Química. \\ E-mail para contato: mariana_lopes10@hotmail.com
}

\begin{abstract}
RESUMO - A demanda por bioetanol é crescente e contribui significativamente para a matriz energética do país. Tecnologias que permitam a sua produção de forma sustentável são de suma importância, como a fermentação com alto teor de etanol, que resulta em vantagens econômicas, sociais e ambientais. Em busca de menor gasto energético na produção do etanol, menor consumo de água, menor produção de vinhaça e redução nos níveis de contaminação bacteriana nas fermentações, o objetivo deste trabalho foi estudar a influência da temperatura na resistência da levedura Saccharomyces cerevisae Y904 ao etanol no processo fermentativo. Os resultados preliminares de fermentações batelada e batelada alimentada realizadas em 20,25 e $32{ }^{\circ} \mathrm{C}$ indicaram que as temperaturas mais baixas favoreceram o processo em termos de conteúdo e produção de álcool, mas resultou em tempos de fermentação mais elevados. A $25{ }^{\circ} \mathrm{C}$ no processo descontínuo com alimentação, a concentração de etanol atingiu $17,36{ }^{\circ} \mathrm{GL}$ (concentração volumétrica álcool, v/v).
\end{abstract}

\section{INTRODUÇÃO}

O Brasil, desde o início de 1970, tem sido o principal produtor de etanol no mundo, utilizando a cana-de-açúcar como matéria-prima. Etanol a partir da cana-de-açúcar com a sua natureza biorrenovável já é um recurso que o Brasil pode utilizar como um dos substitutos para os combustíveis fósseis (Luo, Voet e Huppes, 2009). A produção brasileira de bioetanol tem crescido substancialmente, numa taxa de crescimento muito acima da expansão da área agrícola empregada para a cultura da cana. Este fato se deve aos avanços tecnológicos alcançados, tanto na área agrícola, como na área industrial. Nesta, os processos de fermentação alcoólica evoluíram a partir dos sistemas em batelada com separação de fermento do vinho dos anos 1930, aos processos batelada alimentada e contínuos empregando centrífugas eficientes, com recirculação e com tratamento de fermento. Este fato foi um grande avanço no setor, que aliado à seleção de leveduras de alta capacidade fermentativa, melhorias constantes nos processos produtivos, aumento da eficiência energética do setor, avanços nos processos de destilação, autonomia nacional na produção de equipamentos e insumos, fez com que a indústria brasileira do etanol de 


\section{9 a 22 de outubro de 2014 \\ Florianópolis/SC}

primeira geração utilizando cana de açúcar como matéria prima, seja uma das mais competitivas e mais modernas do mundo (Andrietta et al.,1999).

Numa produção industrial de etanol viável, o processo de fermentação deve ser extremamente robusto e pouco afetado por pequenas alterações da matéria prima, além da minimização dos custos, obtenção do máximo rendimento em etanol, minimização na síntese de outros produtos (como glicerol e ácido láctico), minimização do tempo de fermentação, baixa contaminação bacteriana (ações preventivas, como tratamento ácido do fermento), manutenção da alta viabilidade do fermento, minimização da adição de produtos químicos (como ácidos, antibióticos e antiespumantes), minimização dos gastos com manutenção (como limpeza e vazamentos), minimização de gastos de energia e água, automatização das operações manuais (como monitoramento de temperatura, brix e pH) (Goldemberg et al.,2008; Missawa, 2009).

A fermentação descontínua pode levar a baixos rendimentos e/ou produtividades, quando o substrato adicionado de uma só vez no início da fermentação exerce efeitos de inibição, repressão, ou desvia o metabolismo celular a produtos que não interessam (Carvalho; Sato, 2001a). O biorreator batelada será sempre usado como base para as comparações de eficiências atingidas com relação aos outros processos, mas a sua baixa eficiência estimula o surgimento de formas alternativas (Schimidell; Facciotti, 2001). Os processos batelada alimentada nas suas várias modalidades têm se mostrado eficientes e versáteis na grande maioria dos processos fermentativos, inclusive nos de fermentação alcoólica. Em tais processos, especialmente naqueles com altas densidades celulares, a produtividade é alta devido ao grande número de células viáveis no meio em fermentação. A batelada alimentada permite o controle da concentração de açúcar, minimizando os efeitos de inibição pelo substrato e permitindo a adição do mesmo nos momentos mais propícios durante a fermentação (Mcneil; Harvey, 1990).

Diferentes temperaturas afetam de forma distinta a atividade metabólica e o crescimento da levedura. Isso pode ser atribuído, não somente à genética das diferentes cepas, mas também à composição do meio de crescimento e a outros parâmetros como $\mathrm{pH}$, agentes químicos, desidratação osmótica, estado nutricional e fase de crescimento. As temperaturas ótimas para a produção industrial de etanol situam-se na faixa de 26 a $35^{\circ} \mathrm{C}$, mas, não raramente a temperatura nas destilarias alcança $38^{\circ} \mathrm{C}$. À medida que a temperatura aumenta, a contaminação bacteriana é favorecida e a levedura fica mais sensível à toxidez do etanol, o que implica uma diminuição da viabilidade das células (Lima et al.,2001).

As fermentações conduzidas a temperaturas mais baixas podem levar a uma maior resistência da levedura ao teor de etanol final e também uma menor geração de subprodutos do metabolismo celular devido ao menor estresse ao qual as células são submetidas. Assim, o objetivo deste estudo foi avaliar a influência da temperatura no desempenho de uma estirpe selecionada de Saccharomyces cerevisiae. Comparou-se a atividade do fermento, em processo batelada e batelada alimentada a $32^{\circ} \mathrm{C}$, que é a temperatura usual de muitas plantas brasileiras, com 20 e $25^{\circ} \mathrm{C}$, em termos de conteúdo de álcool e rendimento da fermentação. 


\section{MATERIAL E MÉTODOS}

A levedura Saccharomyces cerevisiae utilizada neste trabalho foi a cepa industrial Y-904 produzida pela $\mathrm{ABB}$ Brasil. A composição do meio de cultura para as leveduras consistia em sacarose (180 e $300 \mathrm{~g} / \mathrm{L}), \mathrm{KH}_{2} \mathrm{PO}_{4}(5 \mathrm{~g} / \mathrm{L}), \mathrm{MgSO}_{4} \cdot 7 \mathrm{H}_{2} \mathrm{O}(1 \mathrm{~g} / \mathrm{L}), \mathrm{NH}_{4} \mathrm{Cl}(1,5 \mathrm{~g} / \mathrm{L}), \mathrm{KCl}(1 \mathrm{~g} / \mathrm{L})$ e extrato de levedura $(6 \mathrm{~g} / \mathrm{L})$. Os reagentes utilizados foram todos de grau analítico, exceto para a sacarose, a qual foi substituída por açúcar cristal comercial.

As fermentações foram conduzidas em um mini-fermentador New Brunswick modelo Multigen, com capacidade útil de 1,5 L, equipado com controle de temperatura e de agitação.

Os experimentos para determinar a resistência da levedura ao etanol foram realizados em processo batelada e batelada alimentada. Fermentações com a concentração inicial de sacarose de $180 \mathrm{~g} / \mathrm{L}$ foram conduzidos em processo descontínuo. Nas fermentações realizadas em batelada alimentada, a alimentação de sacarose foi feita quando no reator a concentração de sacarose era próxima de zero. O total de sacarose alimentada correspondeu a uma concentração de $300 \mathrm{~g} / \mathrm{L}$, se o reator fosse operado em batelada com o seu volume útil 1,5 L.

As concentrações de açúcares (sacarose, glicose e frutose), etanol e glicerol em todos os experimentos foram analisadas por cromatografia líquida de alta eficiência (CLAE) em sistema cromatográfico marca Shimadzu modelo LC-20A Prominence, coluna Supelcogogel-Ca e detecção por índice refração. A solução de arraste foi água deionizada, com a vazão da bomba de $0,5 \mathrm{~mL} / \mathrm{mim}$, temperatura do forno de $80^{\circ} \mathrm{C}$ e volume de injeção de 20 microlitros.

\section{RESULTADOS E DISCUSSÃO}

A Figura 1 mostra os perfis de concentração de sacarose e etanol nos experimentos conduzidos em batelada com concentração inicial de $180 \mathrm{~g} / \mathrm{L}$ de sacarose e concentração inicial de inoculo $9 \%$ v/v, sem qualquer adaptação da levedura nas temperaturas de 20 e $25^{\circ} \mathrm{C}$.
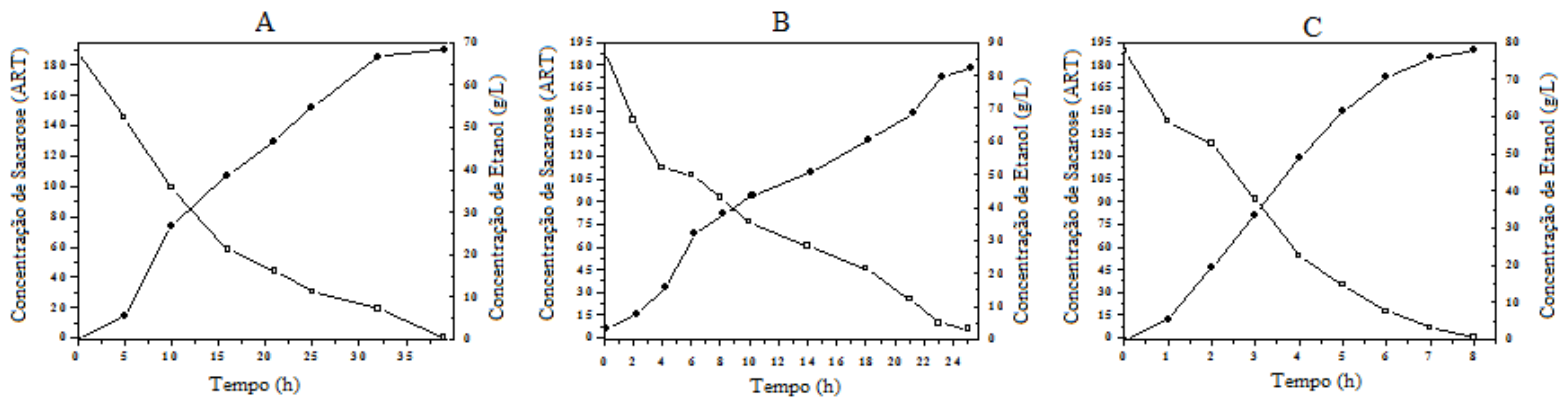

Figura 1 - Perfis de concentração de sacarose $(\square)$ e concentração de etanol $(\bullet)$ em função do tempo, para o Experimento A realizado a $20^{\circ} \mathrm{C}$, Experimento B realizado a $25^{\circ} \mathrm{C}$ e Experimento $\mathrm{C}$ realizado a $32^{\circ} \mathrm{C}$. 


\section{LCoseg}

19 a 22 de outubro de 2014

Florianópolis/SC

Na Figura 1A, são mostrados os resultados da fermentação realizada a $20{ }^{\circ}$ C. Após 39 horas de fermentação o teor alcoólico de $8,64{ }^{\circ} \mathrm{GL}$ foi atingido com rendimento alcoólico de $70,38 \%$. A $25^{\circ} \mathrm{C}$, na Figura 1B, o tempo de fermentação foi reduzido para 25 horas, o teor alcoólico atingiu $11,3{ }^{\circ} \mathrm{GL}$ e rendimento de $92,6 \%$. Aos $32{ }^{\circ} \mathrm{C}$, o tempo para o consumo total do açúcar foi de 8 horas, o teor de álcool chegou a $9,86^{\circ} \mathrm{GL}$ e, o rendimento da fermentação foi de $80,31 \%$. Estes resultados mostraram um considerável aumento no tempo de fermentação com a diminuição da temperatura chegando a mais de 4 vezes quando se comparam as temperaturas de $32{ }^{\circ} \mathrm{C}$ e $20{ }^{\circ} \mathrm{C}$. Após adaptação da levedura, realizando fermentações sucessivas a $20{ }^{\circ} \mathrm{C}$, recuperando e reutilizando a levedura centrifugada, os resultados após a terceira fermentação foram mais satisfatórios em comparação com os resultados da Figura 1A, com tempo de fermentação de 25 horas, teor alcoólico de $10,4^{\circ} \mathrm{GL}$, e rendimento de $87,4 \%$. Este teor de álcool obtido foi consistente com os resultados industriais, para a concentração inicial de sacarose de $180 \mathrm{~g} / \mathrm{L}$.

A fim de se obter concentrações mais elevadas de etanol no caldo fermentado foram realizados experimentos nas mesmas temperaturas 20,25 e $32{ }^{\circ} \mathrm{C}$, em batelada alimentada. $\mathrm{O}$ açúcar foi adicionado ao reator na forma de solução concentrada, sempre que a concentração de açúcar chegava a valores mínimos. Nesses experimentos, a levedura usada não sofreu qualquer processo de adaptação. Os resultados são mostrados na Figura 2.
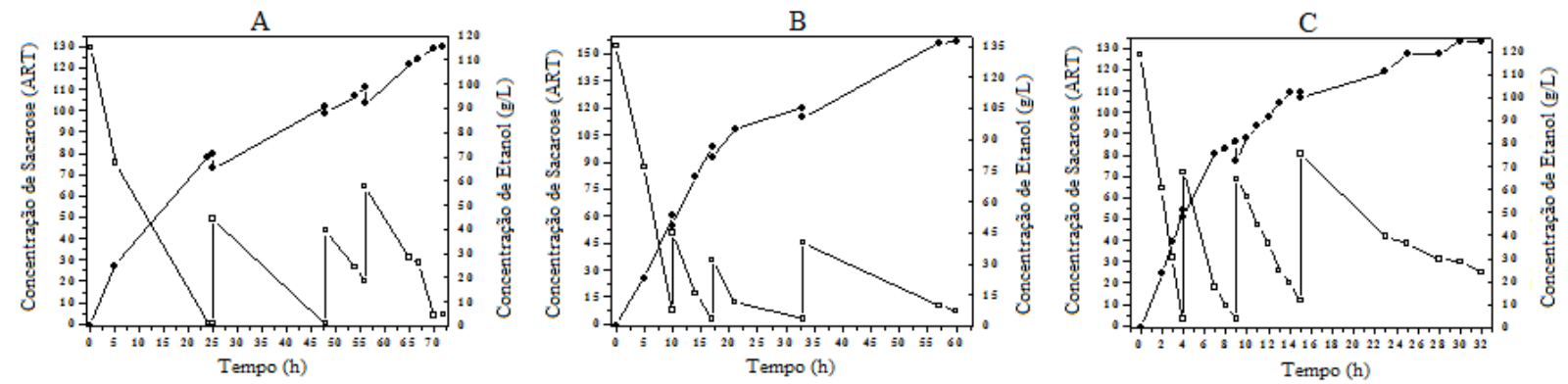

Figura 2 - Perfis de concentração de sacarose ( ( ) e concentração de etanol (•) em função do tempo, para experimentos conduzidos em batelada alimentada. Experimento A realizado a $20^{\circ} \mathrm{C}$, Experimento B realizado a 25 ${ }^{\circ} \mathrm{C}$ e Experimento $\mathrm{C}$ realizado a $32{ }^{\circ} \mathrm{C}$

Após completar o volume do reator por batelada alimentada, a concentração de sacarose correspondeu a $300 \mathrm{~g} / \mathrm{L}$ em processos de batelada convencionais. Na Figura $2 \mathrm{~A}$, os resultados obtidos a $20^{\circ} \mathrm{C}$, indicaram um tempo de fermentação de aproximadamente 72 horas, teor alcoólico de $14,62{ }^{\circ} \mathrm{GL}$ e um rendimento de $78,5 \%$. Para a fermentação realizada a $25{ }^{\circ} \mathrm{C}$, representada na Figura 2B, apresenta tempo de fermentação de 60 horas, teor de alcoólico de $17,36{ }^{\circ} \mathrm{GL}$, e rendimento de $85 \%$. Já a $32{ }^{\circ} \mathrm{C}$ representado na Figura $2 \mathrm{C}$, o tempo de fermentação foi de 32 horas, atingindo $15,73{ }^{\circ} \mathrm{GL}$, com um rendimento de 83,6 \%. Estes resultados indicam que a levedura usada nas fermentações, que é também utilizada industrialmente na produção de etanol, possui uma boa tolerância ao etanol na gama de temperaturas estudada. Os tempos de fermentação foram bastante elevados, mas estratégias de alimentação no processo em batelada alimentada é uma variável que está sendo estudada. As concentrações de etanol, utilizando esta estratégia de batelada alimentada, obtidas neste estudo podem ser consideradas como parâmetro 
para a tolerância ao etanol na modelagem cinética na respectiva temperatura. As concentrações finais de glicerol foram de 4,56 g/L para a fermentação realizada a $20{ }^{\circ} \mathrm{C}$ e de cerca de $10,0 \mathrm{~g} / \mathrm{L}$ para as fermentações realizadas a 25 e $32{ }^{\circ} \mathrm{C}$, o que indica que a levedura pode esta sofrendo um possível estresse a temperaturas elevadas. Outro aspecto a ser considerado é o elevado valor da concentração de substrato usado (300 g/L).

\section{CONCLUSÃO}

Com os resultados apresentados com a cepa Saccharomyces cerevisiae Y904 é possível concluir que, nos processos de fermentação a temperaturas mais baixas, a resistência ao etanol é maior. Outro aspecto evidenciado no processo em batelada alimentada é a possibilidade de se obter concentrações de etanol superiores no caldo de fermentação, quando em comparação com o processo batelada convencional. Comparando-se as concentrações de glicerol a $20{ }^{\circ} \mathrm{C}$, com as alcançadas em temperaturas mais elevadas, 25 e $32^{\circ} \mathrm{C}$, é possível concluir que nas temperaturas mais baixas, o estresse causado pelo etanol é menor.

\section{AGRADECIMENTOS}

Os autores agradecem à Universidade Federal de Uberlândia e à Faculdade de Engenharia Química pela oportunidade em realizar este trabalho. Agradecem também ao apoio financeiro da Fapemig, da CAPES e do CNPq.

\section{REFERÊNCIAS BIBLIOGRÁFICAS}

ANDRIETTA, S. R.; MIGLIARI, P. C.; ANDRIETTA, M. G. S. Classificação de cepas de levedura de processos industriais de fermentação alcoólica utilizando capacidade fermentativa. STAB- Açúcar Álcool e Subprodutos, v. 17, p. 54 - 59, 1999.

CARVAlHO, J. C. M.; SATO, S. Fermentação Descontínua. In: Schmidell, Willibaldo et al. (Coord.). Biotecnologia Industrial: Engenharia Bioquímica. São Paulo: Edgar Blücher, 2001a. p. 193-204. (Biotecnologia Industrial; v.2)

GOLDEMBERG, J.; COELHO, S. T.; GUARDABASSI, P. The sustainability of ethanol production from sugarcane. Energy Policy, v. 36, p. 2086-2097, 2008.

LIMA, U. A.; BASSO, L. C.; AMORIM, H. V. In: LIMA, U. A. (Coord.). Biotecnologia Industrial: Processos Fermentativos e Enzimáticos. São Paulo: Edgard Blücher, 2001. p.1-43. (Biotecnologia Industrial; v.3) 
LUO, L.; VOET, E. van der.; HUPPES, G. Life cycle assessment and life cycle costing of bioethanol from sugarcane in Brazil. Renewable and Sustainable Energy Reviews, v. 13, p. 1613-1619, 2009.

McNEIL, B. e HARVEY, L. M. Fermentation - a practical approach. $1^{\text {st }}$ ed. IRL PRESS at Oxford University Press. 1990.

MISSAWA, S. K. Modificação de linhagens industriais de Saccharomyces cerevisiae para o aumento da produtividade de álcool e floculação condicional. $150 \mathrm{f}$. Tese (Doutorado em genética e Biologia Molecular) - Instituto de Biologia, Universidade Estadual de Campinas, Campinas, 2009.

SCHMIDELL, Willibaldo; FACCIOTTI, Maria Cândida Reginato. Biorreatores e Processos Fermentativos. In: Schmidell, Willibaldo et al. (Coord.). Biotecnologia Industrial: Engenharia Bioquímica. São Paulo: Edgar Blücher, 2001. p. 179-192. (Biotecnologia Industrial; v.2) 